\title{
Planejamento e metropolizaçáo do lazer marítimo em Fortaleza-Ceará, Nordeste do Brasil
}

Alexandre Queiroz. Universidade Federal do Ceará, Fortaleza, Brasil.

RESUmo | A ocupação do litoral metropolitano do Nordeste do Brasil é, na contemporaneidade, dinamizada por atividades de lazer, dentre elas a vilegiaturas (via segundas residências) e o turismo. O planejamento destes espaços é entrecruzado entre as dimensões públicas e privadas, destacando-se o pensamento técnico-urbanístico na definição da lógica de produção do espaço. Este texto tem como objetivo principal entender os meandros do planejamento em uma regiáo metropolitana no Nordeste, mais especificamente Fortaleza, no Estado do Ceará. Para tanto, foi testada metodologia quantitativa e qualitativa na obtenção e tratamento de informaçóes e dados: entrevistas, consulta de documentos técnicos e trabalhos de campo. Após realização dos procedimentos e análises, concluiu-se que o planejamento técnico dos empreendedores e o posicionamento dos governos locais apontam para consolidação da fragmentação espacial do tecido urbano litorâneo. Situação articulada à promoção de modelos urbanísticos que valorizam o uso dos espaços privados em detrimento do espaço público.

PALAVRAS-CHAVE | expansão urbana, morfologia urbana, planejamento urbano.

ABSTRACT | The occupation of the metropolitan coast in the Northeast of Brazil is nowadays dynamized by leisure activities, including summer vacations (through second dwelling) and tourism. The planning of these spaces pervades the public and private dimensions with emphasis on the technical-urbanistic thought which defines the space production logic. The present article aims to understand the meanders of this planning, more specifically in a northeast metropolitan region - Fortaleza, in the State of Ceara. In order to do so, both quantitative and qualitative methodologies were tested to obtain and process data and information: interviews, consultation of technical documents, and fieldwork. After performing the procedures and analyses, it has been concluded that the technical planning of entrepreneurs and the positioning of local governments point to the consolidation of spatial fragmentation in the coastal urban fabric. This situation articulates with the promotion of urbanistic models, which value the use of private spaces to the detriment of public space

KEYWORDS | urban sprawl, urban morphology, urban planning. 


\section{Introduçáo}

O litoral do Nordeste brasileiro, desde os anos 1990, é reconhecidamente um espaço planejado para as práticas marítimas modernas (turismo e vilegiatura/segunda residência). Os elementos apontados por Dantas (2013) indicam o quão relevantes estes processos assumem na contemporaneidade à medida que contribuem para a reestruturação do papel das metrópoles litorâneas brasileiras posto alterarem a hierarquia que caracteriza a rede urbana em destaque. Em decorrência, ocorre uma interconexão entre o processo de urbanização do território associado ao adensamento das atividades de lazer no espaço litorâneo metropolitano, principalmente nas três principais metrópoles da Região (Salvador, Recife e Fortaleza).

Em outros escritos priorizamos a compreensão do processo no Nordeste brasileiro, principalmente ao analisar a localização do quantitativo de domicílios de uso sazonal, as políticas públicas de "tecnificação" do território, os novos empreendimentos do tipo resort e complexo turístico-imobiliário instalados nas bordas litorâneas metropolitanas (Pereira, 2014). De fato, muitos são os fenômenos que podem ser considerados vetores de metropolização. Tais dinâmicas transitam entre dimensóes sociais, econômicas, políticas e culturais e, desta maneira, promovem as inter-relaçóes entre os municípios componentes da regiáo metropolitana, cimentando interdependências (com intensidades e temporalidades diferenciadas), sobretudo com a cidade Polo: a demanda por lazer promove significativamente as chamadas espacialidades metropolitanas.

$\mathrm{Na}$ região Nordeste os espaços metropolitanos, diante de fragilidades político-econômicas de centros urbanos secundários, tornam-se mais enfaticamente espaços de comando da hierarquia urbana (Instituto Brasileiro de Geografia e Estatística [IBGE], 2008). A constituição da Regiâo Metropolitana de Fortaleza (RMf) é exemplo cabal desse quadro (Silva, 2007). Em termos demográficos, a RM de Fortaleza concentra 42,8\% de seu estado (IBGE, 2011). Com produto interno bruto superior a $\mathrm{R} \$ 43$ bilhóes, a RMF abarca $67,7 \%$ de toda a riqueza produzida no estado (Instituto de Pesquisa e Estratégia Econômica do Ceará [IPECE], 2012).

No caso da metropolização em Fortaleza-Ceará-Brasil, a faceta litorânea, a costa atlântica, deve ser lembrada como uma das suas mais importantes condicionantes. Relevante sobremaneira para a efetivação de uma espacialidade do lazer metropolitano, a ambiência litorânea permite, nos padróes atuais, o desenvolvimento das práticas marítimas modernas que se manifestam espacialmente através do processo de metropolização em função do lazer. Se nos anos 1970 e 1980 pode-se apontar a participação de gate-keepers na formação das condiçóes balneárias dos lugares metropolitanos, a partir dos anos 1990, a produção interna destes lugares fragmentou-se na ação de diferentes empresas promotoras imobiliárias. As dinâmicas são variadas e os processos se complexificam. Assim, o roteiro analítico deste artigo debate as diversas, e mesmo contraditórias, percepçóes da valorização do litoral. Incontestavelmente, este processo não envolve apenas empreendedores imobiliários e vilegiaturistas, ou vacanciers em termos mais amplos. Aqui serão pensados os desdobramentos deste fenômeno. 
Neste sentido, é relevante considerar as "ideas-força" que marcam as ações e os discursos dos agentes envolvidos no planejamento dos espaços litorâneos metropolitanos. Objetiva-se, pois, expor e avaliar o entendimento de arquitetos/urbanistas, técnicos do poder público municipal e de moradores dos lugares litorâneos dos desdobramentos advindos da metropolização do lazer marítimo no espaço metropolitano de Fortaleza (municípios de Aquiraz, Caucaia, Cascavel e São Gonçalo do Amarante). Na elaboração de novos caminhos explicativos, essa escolha metodológica relaciona os olhares técnico-burocráticos, às observaçôes do cotidiano, fundamentadas nos saberes populares, compreendendo desta forma a (re)produção do espaço urbano.

Em termos de metodologia operacional, utilizou-se de instrumentos quantiqualitativos, com intuito de compreender as múltiplas visóes dos outros sujeitos ou segmentos sociais que interagem com o conteúdo socioespacial da vilegiatura marítima e das demais práticas marítimas modernas. Destacaram-se três conjuntos de agentes: (i) os olhares e percepçôes daqueles que pensam e propóem os modelos urbanísticos (planejadores/urbanistas); (ii) os que controlam os usos e a efetivação da legislação urbana (técnicos municipais), e (iii) os produtores da praia enquanto lugar de moradia (moradores das localidades).

Para tecer indicadores acerca do primeiro conjunto de agentes resolveu-se acolher duas estratégias: (i) entrevistar arquitetos e urbanistas envolvidos com a produçáo de projetos para os empreendedores imobiliários, assim como, outros relacionados ao ensino e a pesquisa científica no Estado; (ii) Identificar os empreendimentos turístico-imobiliários construídos na costa metropolitana e compará-los aos modelos indicados pelo Projeto de ordenação da costa brasileira.

No intuito de compreender o papel fiscalizador e planejador dos municípios metropolitanos foram contatados representantes técnicos das secretarias de turismo dos quatro municípios, sendo em seguida, proposto o preenchimento de um formulário-síntese para avaliação dos impactos promovidos pela ocupação do litoral pelas segundas residências e seus usuários; também foram analisados os Planos Diretores Urbanos de cada município com intuito de identificar os apontamentos quanto ao uso e a ocupaçáo dos espaços costeiros metropolitanos.

Para os moradores das localidades fez-se uso de entrevistas semi-estruturadas, ou seja, partiu-se de questôes pré-elaboradas, sendo o interrogatório reconduzido em função das formas pelas quais os assuntos e as temáticas eram enfatizadas e/ou hierarquizadas pelos entrevistados. O papel do entrevistador foi o de estabelecer elos, elaborando novas questóes a respeito do modo de vida local e suas relaçóes com a presença dos vilegiaturistas nacionais e estrangeiros.

Os resultados desta pesquisa estão expostos nas três secções a seguir, iniciando pelas características das novas formas de ocupação do litoral e a crítica aos projetos urbanísticos. Na sequência o enfoque será dado ao poder público local, com destaque às concepçóes técnicas, os planos diretores como demonstração de poder político na indução de usos específicos. Por fim, as práticas socioespaciais são mencionadas mediante a compreensão das falas dos moradores das localidades litorâneas da RMF. 


\section{A ocupação do litoral e a crítica aos projetos urbanísticos}

Os dados mapeados na figura 1 identificam os quantitativos e tipologias de domicílios particulares cadastrados pelo Censo oficial de 2010. Nos quatro municípios formadores do espaço estudado são destacadas as 17 localidades litorâneas e os quantitativos de domicílios particulares vagos, ocupados e de uso ocasional (considerados segundas residências). Em Aquiraz e Caucaia concentram-se os maiores quantitativos, sendo que nas localidades de Cumbuco e Porto das Dunas instalam-se os empreendimentos com centenas de unidades a venda. Os domicílios de uso ocasional representam importante definidor da urbanização nestes lugares, à medida que atraem fluxos sazonais de vilegiaturistas e trocas, principalmente as relativas ao mercado de imóveis, haja vista, o significativo número, também, de domicílios vagos (em maioria dispostos a venda e a locação). Tal situação resultada de um cumulativo de processos que duram aproximadamente 50 anos. Compóem-se um espaço litorâneo caleidoscópico, marcado pela diversidade de usos e conflitos socioespaciais.

FIGURA I | Localização de domicílios ocupados, não ocupados e vagos, segundo as localidades litorâneas dos municípios de Aquiraz, Cascavel, Caucaia e São Gonçalo do Amarante, 2010

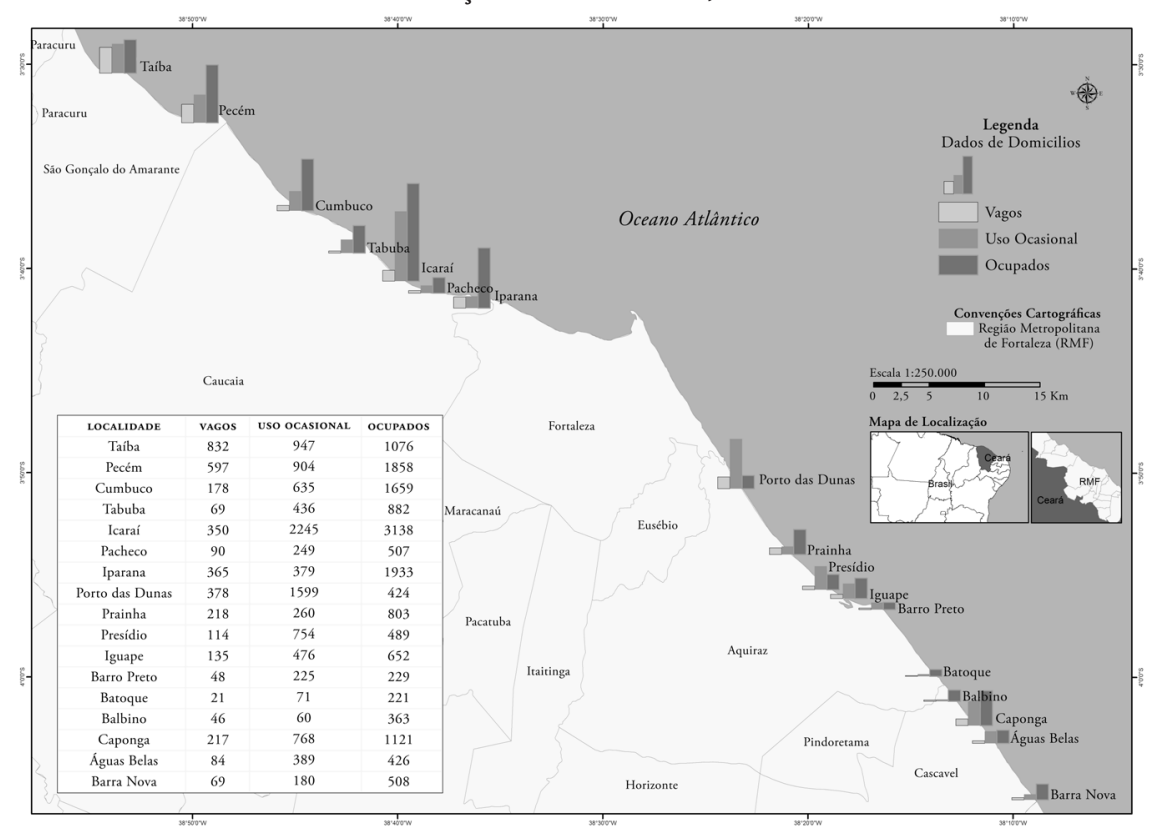

FONTE ELABORADO PELO AUTOR. BASE DE DADOS: SINOPSE DO CENSO (IBGE, 2O I )

A situação do espaço metropolitano de lazer em Fortaleza tem impactos proporcionais à população residente dos municípios envolvidos (entre $40 \mathrm{mil} \mathrm{e} 300 \mathrm{mil}$ habitantes, conforme tabela 1). Sendo ainda relevante considerar o papel dos lazeres 
na constituição do parque imobiliário e nas formas urbanas presentes no recorte litorâneo destes municípios. É uma questão de escala, não a cartográfica, mas a geográfica, ou seja, àquela onde se percebe a intensidade do fenômeno frente o recorte da realidade estudado. O parque imobiliário destinado ao lazer (e/ou mobilizado em função dele) representa nestas localidades razão para ocupação de mais de 50\% de seu território, posto fundamentarem-se em padrão de incorporação espacial horizontal, linear e descontínuo.

Em princípio, os direcionamentos da valorização dos espaços litorâneos sobre o planejamento urbanístico para o caso metropolitano cearense (nordeste do Brasil) remetem ao que Lefebvre (2001) denominou de 'urbanismo dos promotores de venda'. Os planejadores desta categoria calculam pretensos "lugares de felicidade numa vida quotidiana miraculosa e maravilhosamente transformada” (ibídem, p. 25). Em raciocínio semelhante, Harvey (2004) analisa a produção das utopias da forma espacial. Ao examinar uma série de exemplos (a Disneylândia, os megashopping, os subúrbios), o autor os relaciona ao que Louis Marin denominou de utopias degeneradas, formas constituídas por "ambientes protegidos, seguros, bem organizados, de fácil acesso e, sobretudo, agradáveis, relaxantes e isentos de conflito” (ibídem, p. 220). A metropolização do lazer, entendida enquanto processo, remete produção de formas espaciais e urbanísticas com tais características e que tem se tornado marcas intrínsecas ao espaço litorâneo metropolitano nordestino.

Noutros espaços litorâneos mundiais destinados ao lazer (turismo e vilegiatura), em virtude da degradação ambiental e territorial, parâmetros inibidores da ocupação costeira são discutidos e apontados como medidas necessárias (Daligaux, 2003; Cumbrera \& Lara, 2010).

O Projeto de Gestão Integrada da Orla Marítima (Projeto Orla), proposto em 2002 pelo Governo Federal brasileiro, objetivou induzir as municipalidades costeiras a elaborar planos para mediar o uso e a ocupação de seus litorais. O documento evidenciou as estratégicas e funçóes política, social e econômica da orla marítima e, concomitantemente, destacou a variedade de cenários observáveis para os seus mais de $8.500 \mathrm{~km}$ de extensão. O lazer e as atividades turísticas ganharam notoriedade posto sua capacidade na produção de feições/relaçóes nas diversas localidades, integrando-os ao processo de urbanização.

A figura 2 exibe croquis representativos dos modelos urbanísticos mais comuns nos balneários brasileiros, resultados tanto de planejamento urbanístico como das açôes de governos estaduais/municipais e demais agentes sociais. No espaço periurbano de Fortaleza destacam padróes horizontais e de verticalização baixa (A), com núcleos de comunidades de moradores e parcelamentos de terra promovendo manchas de expansão com ocupação heterogênea (adensamento e rarefação) (B). Se nas capitais litorâneas os calçadóes e as avenidas a beira mar dão o acesso livre a praia, nas comunidades litorâneas da metrópole o padrão verificado é o do acesso indireto $(\mathrm{C})$, com vias estreitas delimitadas ora por conjunto de residências unifamiliares ora por empreendimentos compostos por dezenas de casas e apartamentos. 
FIGURA 2 Modelos e cenários de ocupação do litoral brasileiro

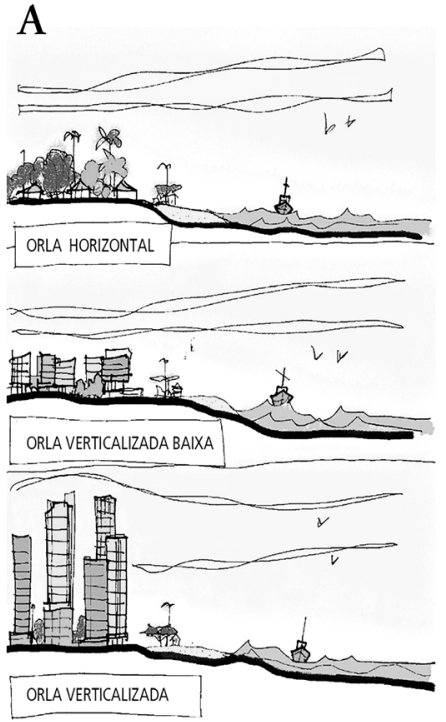

FONTE PROJETO ORLA (2002)

B - PADRÃo PREDOMINANTE DE FEIÇÃo URBANA EM BALNEÁRIOS MARÍtimos (P. 47)

C - Feiçóes urbanísticas e modelos de ACESSo a praia (P. 43)

De acordo com Debié (1993) as primeiras formas urbanas vinculadas ao lazer e a habitação a beira mar originam-se na Europa entre os anos 1850 e 1930. Os passeios, as largas avenidas e os demais espaços públicos tornaram-se modelares a produção do urbanismo nas costas marítimas. Contudo, para o caso brasileiro e, especialmente na metropolização do lazer no Nordeste, o modelo de retaguarda e acesso público a praia eclipsou-se em relação ao modelo de apropriação privado.

$\mathrm{Na}$ avaliação dos urbanistas fortalezenses ${ }^{1}$ não há uma preocupação urbanística para o litoral do estado e da metrópole. A heterogeneidade da ocupação é caracterizada pelo espontâneo e, por assim dizer, ausência de planejamento e desenho urbano. Para o entrevistado 2, no Ceará o potencial paisagístico do litoral não é aproveitado. Segundo o entrevistado, as recomendaçôes da literatura especializada indicam que intervençóes bem sucedidas são àquelas geradoras de impressão de zelo, limpeza, balneabilidade, interação social e enormes oportunidades paisagísticas.

Para os projetistas, a dimensão arquitetônica é considerada individualizada. Neste quesito, na avaliação do entrevistado 5, “embora seja possível identificar relativa qualidade (estética, funcional, técnico-construtiva) em edifícios projetados (residências de veraneio, resorts, pousadas, hotéis) por arquitetos, não são suficientes para qualificar os espaços públicos litorâneos".

1 Para preservar a identidade dos entrevistados, no texto seus nomes serão omitidos e diferenciados por numerais. 
Na avaliação geral, nos trechos litorâneos considerados espaços públicos também não há formalismo urbanístico e arquitetônico. Nas consideraçôes do entrevistado 2 , os elementos comuns, calçadas, praças, esplanadas e barracas de praia, tem padróes indiferentes ao contexto urbano próximo, o que contribui para a sua consequente deteriorização. $\mathrm{O}$ ato mais democrático seria a manutenção de áreas de livre acesso "cheias de vida e atividades" (entrevistado 2).

Essas questóes remetem diretamente às tipologias de empreendimentos implantados (complexos turísticos e residenciais, alguns autodenominados de resort), o que conflui para a discussão dos critérios formatados pelos planejadores, em virtude do gosto e a exigência dos futuros compradores e usuários. As consideraçóes desembocam na caracterização de um modelo de urbanização do território próximo às utopias degeneradas: são empreendimentos "de grande porte, com muito luxo, com todos os serviços possíveis e imagináveis. Completamente (sic) voltado para dentro de si, sem nenhuma relação com o entorno" (entrevistado 1), e desta forma, conformam-se "em pequenas cidades de veraneio planejadas através de empreendimentos privados" (entrevistado 3).

A figura 3 exprime mosaico de imagens capaz de exemplificar os atuais padrôes de ocupação e produção do espaço costeiro na região metropolitana de Fortaleza, mais especificamente, em Porto das Dunas (Aquiraz-CE). É observável a expansão da malha urbana paralela à linha de costa, todavia sem prolongamentos das vias públicas (A). O empreendimento Golf Ville garante aos proprietários dos apartamentos um ambiente de lazer fechado e "seguro", com acesso à praia. Nas demais ilustraçóes (B, C e D) visualizam-se os espaços internos em planejamento e em construção, assim as plantas das unidades residenciais.

Um novo vetor na produção do espaço litorâneo é aberto com o planejamento e construção deste tipo de complexo turístico-imobiliário. Tais empreendimentos podem ser comparados a "cidadelas do lazer", posto ocuparem áreas superiores a 200 hectares (em média), sendo conformados por uma diversidade de opçóes para a estada à beira-mar. No Ceará, dois estão em fase de comercialização e com obras infraestruturais prontas: Aquiraz Riviera e Golf Ville, ambos localizados em Aquiraz. Outros em fase de planejamento têm no espaço litorâneo metropolitano também localização preferencial (em destaque Caucaia e Cascavel), demonstrando dessa forma a primazia das relaçóes de integração metropolitana para empreendimentos deste porte.

De acordo com os profissionais, os modelos urbanísticos e as formas arquitetônicas dos empreendimentos (tanto os complexos como os condomínios) atendem a quatro exigências básicas: conforto, práticas homogêneas de lazer, ostentação/ distinção social e, principalmente, segurança. Para o Entrevistado 2, essas exigências condicionam a produção de verdadeiros devaneios, que ao mesmo tempo, excluem uma série de questóes que deveriam encontrar-se como prioridades.

Para um projeto ideal diria que na parte urbanística a preservação das visuais, uma implantação coerente levando em consideração os vizinhos e o entorno urbano, a sensibilidade com a questâo sanitária, a preservação e incrementação da vegetação nativa e para a arquitetura acredito que edificaçóes simples, eficientes, criativas e sem devaneios ou complexos de atençáo... (Entrevistado 2). 
FIgURA 3 | Mosaico descritivo das formas urbanísticas e arquitetônicas dos empreendimentos do tipo turísticos-imobiliário no litoral metropolitano de Fortaleza, 2015

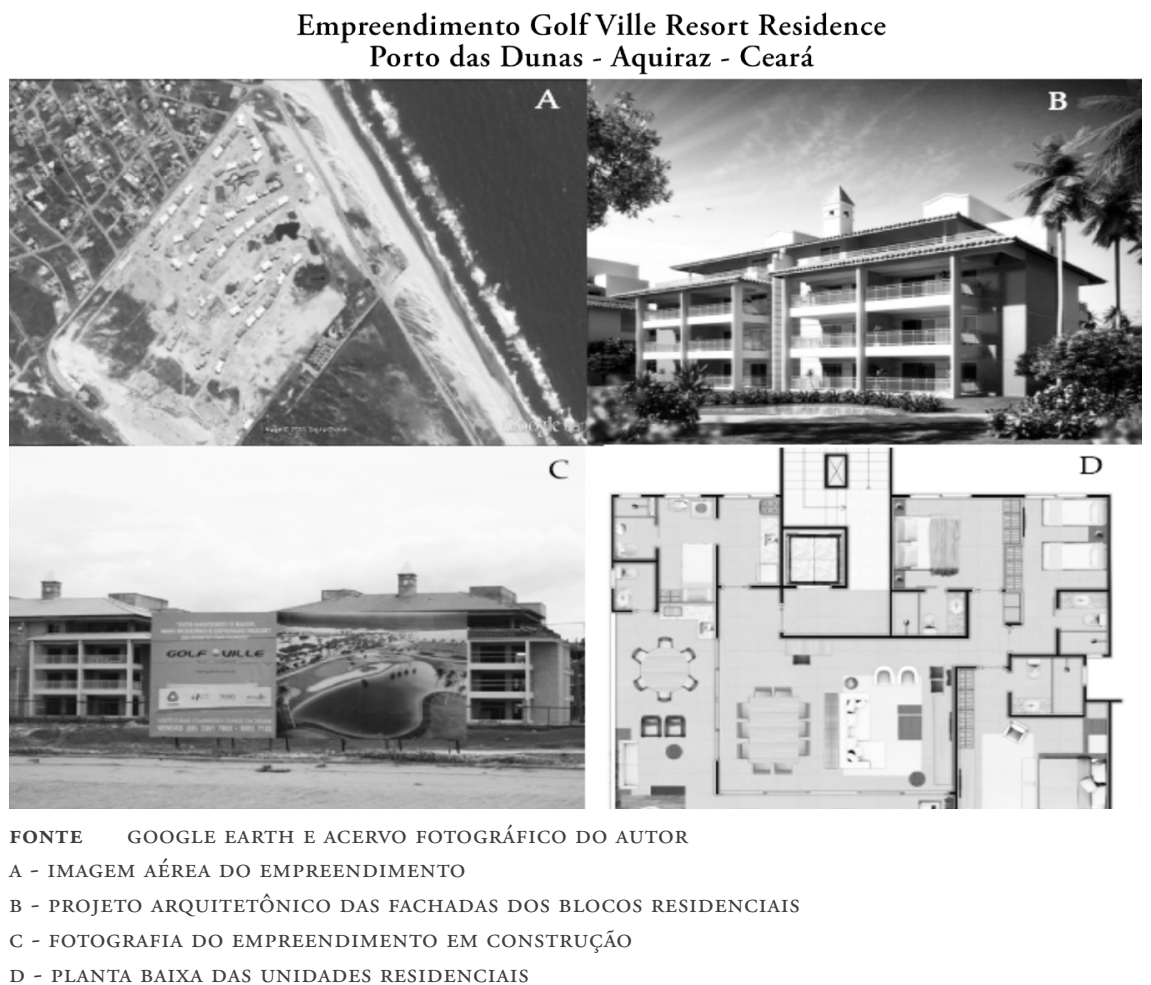

Em termos sintéticos, quatro declarações revelam as múltiplas críticas aos sujeitos determinantes de um quadro que se exibe como problemático.

A falta de planejamento e conscientização da população nativa e mesmo dos políticos têm transformados o nosso litoral em uma grande favela. A grande carência é de infraestrutura (estradas e aeroportos) de serviços agregados (escolas e hospitais). Os loteamentos vão ocupando as áreas indiscriminadamente. Precisamos de mais qualidade em nossos espaços urbanos de litoral se quisermos atrair um turismo que traga renda e melhore o nível de vida da população local (Entrevistado 3).

É fundamental que os arquitetos tenham uma consciência crítica em relação ao tipo de ocupação urbanística e edilícia nos espaços litorâneos e seus impactos sociais e ambientais, para que possam atuar com maior protagonismo junto ao Estado, através do planejamento, planos diretores, desenho urbano e consultorias ambientais e ao mercado, junto às construtoras, incorporadoras e clientes privados. Não é uma tarefa fácil, pois na maioria das vezes contraria os interesses do capital imobiliário (Entrevistado 5). 
Há um consenso no que tange aos equívocos do modo como se produz o espaço urbano no litoral cearense. Critica-se a omissão do poder público, a flexibilidade da legislação, assim como a ausência de fiscalização do realmente efetivado. Admite-se que as municipalidades são incapazes de escolher globalmente as formas urbanas adequadas as características da ocupação anterior do território, inclusive, em harmonia com as paisagens naturais. Nos discursos dos planejadores, erigem críticas ao papel da arquitetura e do urbanismo, considerando-os como conhecimentos a serviço dos interesses dos promotores imobiliários.

Por outro lado, as condenaçôes remetidas aos moradores locais são descabidas. $\mathrm{Na}$ conjugação de forças políticas, estes se demonstram mais enfraquecidos, posto deles ser retirado qualquer instrumento de participação na ordenação do seu lugar. Os ditames advêm das dinâmicas imobiliárias e turísticas locais, nacionais e internacionais que têm promovido o litoral conforme o consumo dos espaços, sendo regido pelo padrão urbano-mercantil de acesso ao solo urbano (Pereira \& Dantas, 2008).

\section{Poder público local: entre a técnica e a política}

Sobre as municipalidades recaem os desdobramentos relativos à valorização do espaço litorâneo. Antes disso, o zoneamento territorial e a indicação dos padróes de uso e ocupação dos espaços, assim como a definição das áreas urbanas propícias a expansão urbana são de responsabilidades destes governos locais. Dessa maneira, por omissão ou por despreparo técnico-político, os municípios incentivam ou, somente, permitem a ocupação do espaço litorâneo, sem, a priori, refletir acerca de possíveis demandas futuras.

O Plano Diretor de Desenvolvimento Urbano (PDDU) é peça técnica e política básica (imposta por lei federal) na condução da ocupação do território municipal no Brasil. Ele indica as zonas de consolidação da urbanização, apontando também para àquelas prioritárias aos investimentos públicos e privados. No caso do litoral metropolitano em análise, todos os municípios elaboraram seus PDDUs com recursos do Governo do Estado. O tabela 1 descreve os principais elementos característicos dos diagnósticos, zoneamentos e projetos estruturantes. Resumidamente, é percebível alinhamento entre o que os processos atuais e o que os PDDus prescrevem e fomentam. Incluem o litoral (ou o espaço litorâneo em termos mais amplos) no contexto metropolitano como front de expansão urbana. Isso implica na possibilidade de consolidação dos processos apontados em tópico anterior, ou seja, o avanço do setor turístico-imobiliário.

Se os Planos Diretores emitem uma impressão geral da ação de médio e longo prazo do poder local, avaliou-se a necessidade de verticalizar a análise e detectar as açóes públicas frente à presença de imobiliário voltado ao lazer e ao turismo. Como as segundas residências e os outros empreendimentos também relacionados a vilegiatura marítima tem forte impacto na produção do espaço litorâneo e sabendo, da extensão temporal do processo, que já demarca período de mais de quatro décadas de expansão, imaginou-se que seria importante identificar a vilegiatura marítima (e demais práticas de lazer) nos diagnósticos e prognósticos das administraçóes locais. 
TABELA I | Caracterização do espaço litorâneo metropolitano conforme elementos descritos nos Planos Diretores

\begin{tabular}{|c|c|c|c|}
\hline MUNICÍPIO & DIAGNÓSTICO & ZONEAMENTO & $\begin{array}{c}\text { PROJETOS } \\
\text { ESTRUTURANTES }\end{array}$ \\
\hline Aquiraz & $\begin{array}{l}\text { Grandes investimentos } \\
\text { imobiliários (Loteamen- } \\
\text { tos, Resorts), culminando } \\
\text { com grande especulaçáo } \\
\text { imobiliária; } \\
\text { Implantaçáo da Reserva } \\
\text { Extrativista do Batoque. }\end{array}$ & $\begin{array}{l}\text { Zonas de Expansão Urbana } \\
\text { - zEU: II - Área Estratégica } \\
\text { de Interesse Litorâneo - AEIL } \\
\text { (Porto das Dunas, Prainha, } \\
\text { Presídio, Iguape, Barro Preto } \\
\text { e Batoque). }\end{array}$ & $\begin{array}{l}\text { Estruturação da faixa litorâ- } \\
\text { nea do Município; } \\
\text { Intervençáo nas Âreas } \\
\text { Críticas. } \\
\text { Requalificação da Via de } \\
\text { Ligação Praia/Sede/Justinia- } \\
\text { no de Serpa. }\end{array}$ \\
\hline Caucaia & $\begin{array}{l}\text { Atração dos Esportes Maríti- } \\
\text { mos (Destaque para Praia do } \\
\text { Cumbuco); } \\
\text { Instalação de Resorts de } \\
\text { Grande Porte (Ex: Vila Galé } \\
\text { Cumbuco). }\end{array}$ & $\begin{array}{l}\text { Zona Urbana - Sede } \\
\text { Municipal, Litoral (Zona } \\
\text { de urbanização restrita pela } \\
\text { fragilidade ecológica). }\end{array}$ & $\begin{array}{l}\text { Obras de recuperação do } \\
\text { dissipador de energia. }\end{array}$ \\
\hline Cascavel & $\begin{array}{l}\text { Investimentos no setor } \\
\text { turístico em pequena escala } \\
\text { (hospedagens, barracas na } \\
\text { praia). }\end{array}$ & $\begin{array}{l}\text { Área 01: Limitada ao norte } \\
\text { pelo Oceano Atlântico, a } \\
\text { leste pelo Rio Choró, ao sul } \\
\text { pela CE-O4o e a oeste pelo } \\
\text { Riacho Mupeba; Área 02: } \\
\text { Definida nos seus limites, } \\
\text { compreende o distrito-se- } \\
\text { de de Cascavel; Área 03: } \\
\text { Compreende a sede distrital } \\
\text { de Caponga. }\end{array}$ & $\begin{array}{l}\text { Urbanização das localidades } \\
\text { litorâneas; Obras de con- } \\
\text { tenção da maré; Implantação } \\
\text { de infraestrutura de acesso } \\
\text { praia de barra nova. }\end{array}$ \\
\hline $\begin{array}{l}\text { S. G. do } \\
\text { Amarante }\end{array}$ & $\begin{array}{l}\text { Implantação do Complexo } \\
\text { Industrial Portuário do } \\
\text { Pecém. Áreas de lazer e } \\
\text { turismo. }\end{array}$ & $\begin{array}{l}\text { Zona de Urbanização Priori- } \\
\text { tária (faixa litorânea da sede } \\
\text { distrital da Taíba). }\end{array}$ & $\begin{array}{l}\text { Urbanização da Faixa Li- } \\
\text { torânea da Sede do Distrito } \\
\text { da Taíba. }\end{array}$ \\
\hline
\end{tabular}

Inicialmente, foi confirmada a noção de que nenhuma das municipalidades mantém quaisquer cadastros ou estudo referente às segundas residências ou casas de veraneio (como são reconhecidas). Em relação a isso, arguiuram-se quais seriam as razóes para tanto. Duas foram apontadas: (i) a consideração de que as segundas residências não são de responsabilidade das municipalidades, e (ii) ausência de pensamento estratégico tangente a esta questáo. A primeira resposta demonstra desconhecimento das atribuiçóes municipais na regência de seu território. A segunda resposta pode ser explicada pelas precariedades no corpo técnico das mencionadas secretarias. Das quatro visitadas, duas não contam com profissionais especializados e permanentemente incluídos na administração. As discussóes que envolvem a instalaçáo de grandes empreendimentos não passam por pareceres técnicos da citada área, sendo definidos em instâncias superiores e com aval eminentemente político e/ou empresarial. Diante das precariedades técnicas e gerenciais, os próprios técnicos entrevistados admitem que numa escala de 1 a 5, onde 1 representa muito importante e 5 sem importância, as segundas residência representam fator 1 na organizaçáo do litoral dos respectivos municípios. 
Inicialmente, os representantes técnicos foram indagados a respeito das relações entre a propagação dos usuários das segundas residências e o desenvolvimento das atividades turísticas. A grosso modo, as respostas dos entrevistados indicaram a consideração de que há uma proximidade entre a evolução de ambos as atividades. As considerações mencionadas insinuam que o uso e a instalação de segundas residências propiciam facilidades para outros turistas, fornece uma fonte de turistas, atrai o turismo doméstico, fornece benefícios econômicos aumentando os que o turismo já atrai, e são capazes de juntos instigarem o desenvolvimento regional.

Para melhor compreender a representação dos impactos propiciados pelas segundas residências e seus usuários, utilizou-se metodologia elaborada por Müller, Hall e Keen (2008). Neste procedimento, os representantes dos governos municipais indicam a relevância das segundas residências sobre efeitos sociais, físico/ ambientais e econômicos, estes subdivididos em dois conjuntos: os positivos e negativos (Tabela 2). A relevância é quantificada em uma escala de cinco níveis (1- muito importante a 5- sem importância). Foram entrevistados quatro técnicos indicados pelas secretarias de turismos dos respectivos municípios metropolitanos litorâneos.

No tangente aos efeitos sociais positivos pode-se destacar a que os governos locais consideram as segundas residências como vetores de modernização e melhoria das condiçôes de vida dos moradores locais, isso se reflete principalmente no peso atribuído as mudanças no estilo de vida da comunidade e a entrada de novas ideias (costumes, técnicas, ideologias políticas, crenças, dentre outras). Em termos negativos são mencionados com maior evidência o aumento da criminalidade, perda de identidade cultural, as propriedades vazias ao longo de determinadas estaçóes e mudanças na estrutura social (formas de organizaçáo comunitária e familiar).

Uma visão mais pessimista é detectada na produção dos efeitos físico-ambientais. Confrontadas as transformaçôes positivas às negativas evidencia-se que mesmo sem diagnósticos específicos, os técnicos destacam condiçôes problemáticas em relação ao depósito de resíduos sólidos, o uso do sistema viário, o uso dos recursos hídricos e a degradação de ambientes naturais vulneráveis (praias, manguezais, dunas). A noção de embelezamento da área, tratada como positiva, refere-se a padronização das construções e dos ambientes artificiais construídos, principalmente em empreendimentos privados e de maior porte (grandes condomínios, resorts e complexos turísticos).

Em termos econômicos, as positividades são apontadas principalmente no setor imobiliário e na criação de empregos. De fato, os maiores valores pecuniários do solo urbano nas municipalidades são constatados nas localidades litorâneas, em destaque nas terras a beira-mar. Ao mencionar a criação de empregos, os entrevistados referem-se ao setor de serviços menos especializados (e com menor carga de conhecimento técnico), ou melhor, os serviços de manutenção, vigilância e limpeza dos imóveis. No Ceará, genericamente, esses trabalhadores domésticos são conhecidos como caseiros. Outros empregos de baixa remuneração (em torno de um salário mínimo, atualmente $\mathrm{R} \$ 880,00)$ são proporcionados pelos empreendimentos de imobiliários e de lazer (camareiros, garçons, vigilantes, zeladores, jardineiros, ajudantes de cozinha, dentre outros). Além desses, os autônomos estão 
também presentes (encanadores, pedreiros, marceneiros, proprietários de pequenos comércios, dentre outros).

TABEla 2 Indicação da relevância dos impactos das segundas residências nos municípios de Aquiraz, Caucaia, Cascavel e São Gonçalo do Amarante

\begin{tabular}{|c|c|c|}
\hline \multicolumn{2}{|r|}{ IMPACTOS } & MODA \\
\hline \multicolumn{3}{|c|}{ EFEITOS SOCIAIS } \\
\hline \multirow{4}{*}{$\begin{array}{l}\stackrel{0}{0} \\
: \begin{array}{c}0 \\
0\end{array} \\
0\end{array}$} & Melhora estilo de vida da comunidade & 1 \\
\hline & Entrada de novas ideias na comunidade & 1 \\
\hline & Criação de facilidades & 1 \\
\hline & Preserva um modo de vida tradicional & 4 \\
\hline \multirow{7}{*}{ 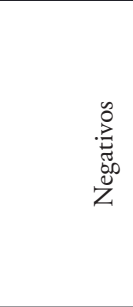 } & $\begin{array}{l}\text { Antagonismos entre proprietários de segundas residências e } \\
\text { moradores locais }\end{array}$ & 3 \\
\hline & Aumenta da criminalidade & 3 \\
\hline & Perda da identidade cultural & 1 \\
\hline & Propriedades vazias nos períodos de baixa estação & 1 \\
\hline & Alteraçóes no estilo de vida tradicional & 2 \\
\hline & Mudança na estrutura social & 2 \\
\hline & Limitaçáo de acesso a praia e demais áreas de recreação & 3 \\
\hline \multicolumn{3}{|c|}{ EFEITOS FÍSICOS/AMBIENTAIS } \\
\hline \multirow{5}{*}{$\begin{array}{l}0 \\
: \\
: 0 \\
0 \\
0 \\
0\end{array}$} & Embelezamento da área & 1 \\
\hline & Proteção de áreas naturais & 3 \\
\hline & Proteção do patrimônio histórico & 1 \\
\hline & Proteção ao modo de vida tradicional & 3 \\
\hline & Surgimento de novos serviços & 2 \\
\hline \multirow{8}{*}{ 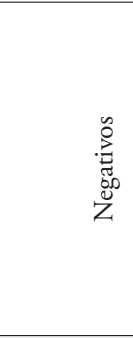 } & Perda das amenidades visuais & - \\
\hline & Eliminação inadequada de resíduos & 1 \\
\hline & Degradação ambiental & 1 \\
\hline & Superutilização do sistema viário & 1 \\
\hline & Desregulaçáo do modo de vida tradicional & 2 \\
\hline & Exploração de áreas naturais & 1 \\
\hline & Uso inadequado de terras em áreas de conservação & 1 \\
\hline & Inadequado abastecimento de água & 1 \\
\hline \multicolumn{3}{|c|}{ EFEITOS ECONÔMICOS } \\
\hline \multirow{6}{*}{ 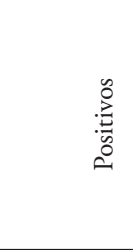 } & Restauração do valor do solo & 1 \\
\hline & Aumento de oportunidades de emprego & 3 \\
\hline & Criação de nova base econômica & 3 \\
\hline & Criação de novos serviços industriais & 4 \\
\hline & Aumento de taxas e impostos & 4 \\
\hline & Contribuição na manutenção dos serviços existentes & 4 \\
\hline \multirow{4}{*}{ 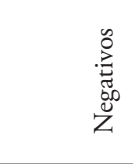 } & Aumento do preço da terra superior a ganhos dos locais & 1 \\
\hline & Aumento do preço das propriedades & 1 \\
\hline & Aumento do custo de bens e serviços locais & 1 \\
\hline & Aumento dos custos para os governos locais & 1 \\
\hline
\end{tabular}


Em relação aos impactos gerados pela captação de taxas e impostos, os gestores municipais relatam dos altos índices de inadimplência por parte dos usuários sazonais proprietários de imóveis. Esta condição se agrega a avaliação do que os valores arrecadados não são suficientes para custear as demandas geradas (maior produção de resíduos sólidos, maiores demandas nos serviços de saúde e prevenção a epidemias, pressão pelo melhoramento das infraestruturas viárias). Estes fatos, tidos como problemas, se ajuntam ao aumento nos preços das propriedades, nas mercadorias e nos serviços nas localidades. Tais condiçôes econômicas atingem, principalmente, as populaçôes residentes que, em suma maioria, tem baixos rendimentos familiares mensais.

É importante lembrar que desde o fim do século xx, os mencionados municípios elaboraram e aprovaram os Planos Diretores de Desenvolvimento Urbano (PDDU), o que deveria, em teoria, significar a produção de diagnóstico dos processos propulsores da urbanização do território municipal e de um arsenal de estudos, fundamentadores de uma gama de normatizaçôes (em destaque, a Lei de Uso e Ocupação e o Código de Obras e Posturas), democraticamente aprovadas pelas Câmaras municipais. Dedutivamente, estes estudos e leis seriam capazes de aumentar o grau de autonomia dos municípios, elevando também a possibilidade de resolver cenários e condiçóes indesejadas para a maioria da população local. No caso específico em análise, as municipalidades demonstram-se frágeis a estes vetores de transformação, não sendo perspectiveis, de curto ou médio prazo, medidas para discutir participativamente o que é ou não de interesse dos munícipes.

\section{Os moradores da praia e suas concepçóes}

As concepçóes pelas quais os grupos e as entidades definem os processos/atividades sáo decisivas no entendimento das transformaçóes socioespaciais. Anteriormente, foram indicadas percepçóes referentes aos técnicos urbanísticos e aos técnicos municipais, nesta seção destaca-se o olhar dos moradores. Como interpretam as atividades que predominam e definem os usos e investimentos nos espaços onde habitam? Qual temporalidade rege os conceitos presentes em seu discurso? Há um único perfil de morador, um pensamento único? Respostas a estas questôes são objetivos deste tópico.

Uma das temáticas mais lembradas ao discutir os espaços litorâneos tropicais são exatamente as relaçóes entre as demandas dos vacanciers (turistas, excursionistas, vilegiaturistas) e a organização social dos moradores destes lugares. Sem equívocos, há uma gama de critérios utilizados para diferenciar estes sujeitos sociais, todavia, na abordagem geográfica do problema, as relaçóes com o lugar em comum contribuem sobremaneira para a elaboração desta distinção. Para Cazelais (2009) os moradores são o parâmetro. Estes detêm conhecimento empírico do lugar e uma forte relação de intimidade (auto-reconhecimento). Para se identificarem, utilizam-se do lugar de moradia como um dos primeiros elementos definidores de sua existência social. Por outro lado as discussóes acerca do nomadismo moderno e da formação das multiterritorialidades, antes de serem condiçôes absolutas, lembram que a condição de morador também é passível da transitoriedade. 
Conforme Cazelais (2009), os moradores detêm "la propriété morale" (sentimento de identificação) e "la propriété foncière" (baseada em instrumentos legais e financeiros). Se em relação ao primeiro aspecto, há certo consenso, isso não se aplica ao segundo, haja vista o crescente movimento mundial de aquisição de imóveis residenciais em função do turismo e da vilegiatura. Espaço-temporalmente, a definição de morador e de vacancier é relacional. $\mathrm{O}$ autor partilha dessa concepção ao afirmar que "des villégiateurs de longue date seront quand même considérés comme des 'étrangers' par les résidents, malgré leurs efforts parfais répétés et soutenus pour s'intégrer" (ibídem, p. 182).

O pensamento de Lefebvre (1991) acerca do cotidiano possibilita uma diferenciação coerente entre os dois sujeitos sociais avaliados. Os vacanciers consideram o espaço-tempo de lazer como uma possibilidade de fuga da cotidianidade, atribuindo a esta situação um papel complementar às suas relaçóes de reprodução. Para os moradores, o mesmo espaço é constituído por uma noção de tempo diferenciada: uma noção de tempo ordinária, sem surpresas, próprias das obrigaçôes cotidianas (trabalho, subsistência).

Exceto Caucaia, ${ }^{2}$ os demais municípios apresentam população total inferior a 75 mil habitantes, todavia com área territorial superior a $400 \mathrm{~km}^{2}$. Deste fato resulta um índice de densidade demográfica reduzido, principalmente se compararmos a Fortaleza (7.786,44 hab./ $\mathrm{km}^{2}$, conforme o IBGE em 2011). A forma de distribuição da urbanizaçáo do território segue duas localizaçóes primordiais: o distrito sede da administração municipal (a cidade) e os espaços beira do oceano atlântico (o litoral). No litoral formam-se localidades base tanto para as comunidades tradicionais (pescadores, marisqueiros, artesãos, etc.) como para a instalação das segundas residências, hotéis e complexos turístico-imobiliários. Desta forma, a urbanização vinculada ao lazer é fato decisivo no entendimento deste recorte metropolitano, ocupando milhares de hectares por dezenas de quilômetros litorâneos (tabela 3).

TABELA 3 | Espaço litorâneo em análise segundo município, população e área territorial

\begin{tabular}{|c|c|c|c|c|}
\hline MUNICÍPIO & POPULAÇÃO & ÁREA $\left(K M^{2}\right)$ & $\begin{array}{c}\text { DENSIDADE } \\
\text { DEMOGRÁFICA } \\
\left(\text { HAB./KM }{ }^{2}\right)\end{array}$ & $\begin{array}{c}\text { EXTENSÃO LINHA DE } \\
\text { COSTA OCUPADA } \\
\text { PELO LAZER (KM) }\end{array}$ \\
\hline Aquiraz & 72.628 & 482,38 & 150,50 & $-17,5$ \\
\hline Caucaia & 325.441 & $1.228,51$ & 264,91 & $-25,3$ \\
\hline Cascavel & 66.142 & 835,00 & 78,79 & $-8,10$ \\
\hline $\begin{array}{l}\text { São Gonçalo do } \\
\text { Amarante }\end{array}$ & 43.890 & 834,45 & 52,60 & $-16,7$ \\
\hline
\end{tabular}

FONTE IBGE, 20 I I

2 O caso de Caucaia é diferenciado à medida que a partir dos anos 1980 foram construídos grandes conjuntos habitacionais contíguo a periferia da cidade de Fortaleza. Tais espaços residenciais foram ocupados por classes populares e que mantém seus empregos em empresas sediadas no polo metropolitano. 
$\mathrm{Na}$ contemporaneidade e para as localidades litorâneas da região Metropolitana de Fortaleza, e quiçá nas demais no Nordeste, a figura do morador não pode ser restringida aos grupos tradicionais (pescadores, marisqueiros, dentre outros). São cada vez mais comuns moradores "recentes" atraídos pelo processo de valorização dos espaços litorâneos e pelas transformaçóes socioeconômicas derivadas. Partindo deste entendimento, durante os trabalhos de campo, foram ouvidos moradores de diferentes perfis (desde aqueles que se afirmaram integralmente nativos até os recentemente instalados). De acordo com dados do censo demográfico de 2010, há um espectro de casos: localidades com 850 habitantes a pequenos bairros com mais de 10.000 moradores (figura 4). Os quantitativos demográficos relativamente reduzidos convivem em meio a imóveis ocupados sazonalmente por outros milhares. O caso de Portos das Dunas no município de Aquiraz é emblemático. As 1200 pessoas recenseadas são multiplicadas dezenas de vezes em períodos de férias ou mesmo em feriados nacionais.

FIgURA 4 População residente, segundo localidades litorâneas dos municípios de Aquiraz, Cascavel, Caucaia e Sáo Gonçalo do Amarante, 2010

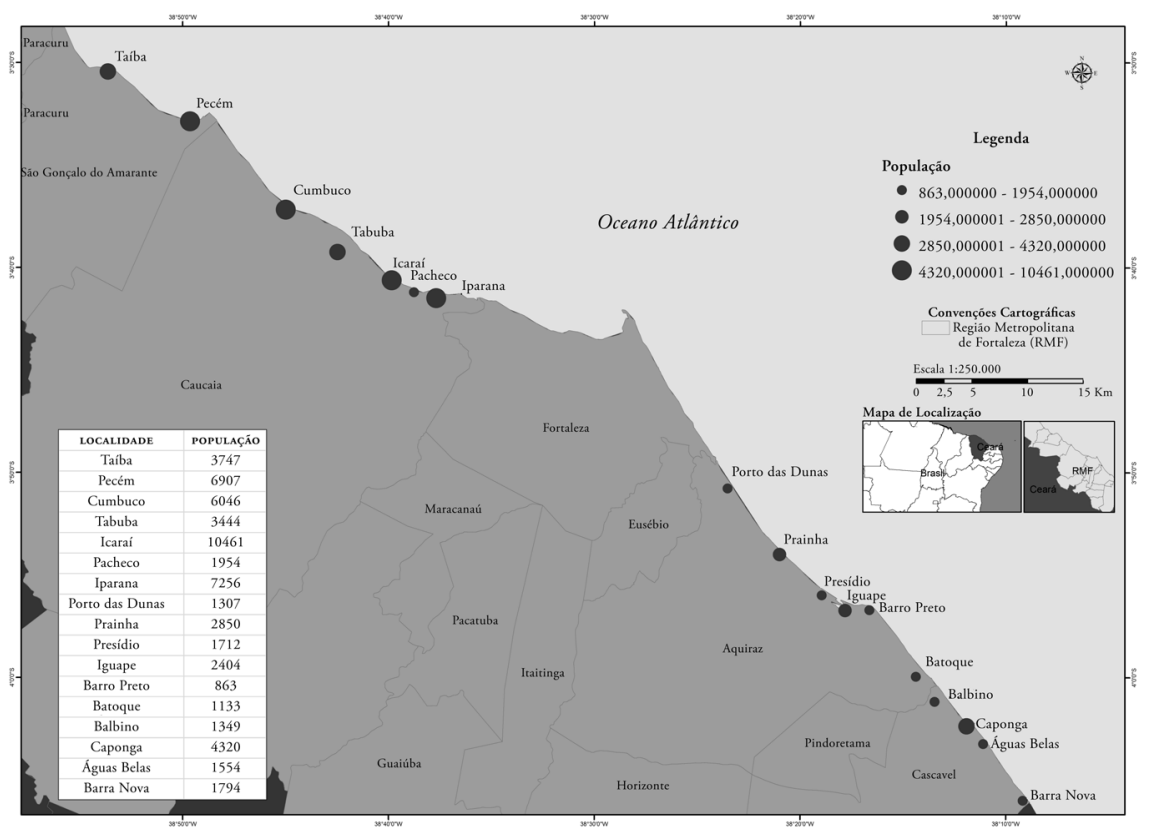

FONTE

ELABORADO PELO AUTOR COM BASE EN: SINOPSE DO CENSO DO IBGE, 2 OI I

Os números absolutos são indicativos da produção destes espaços, contudo para este estudo interessa compreender as concepçóes frente a presença dos vacanciers. Durante as entrevistas foram constatados três perfis de moradores: (i) moradores tradicionais de localidades incorporadas as dinâmicas da vilegiatura e do turismo; (ii) moradores de localidades com movimentos sociais resistentes aos processos aos 
desdobramentos socioeconômicos da maritimidade moderna (principalmente, a mercantilização da terra); e (iii) moradores recentes atraídos exatamente pelas transformaçóes das últimas décadas.

O primeiro grupo é composto, sobremaneira, por pessoas que acompanharam as transformaçôes transcorridas durante os últimos 40/50 anos. $\mathrm{Na}$ fala dos mais idosos é possível observar um ressentimento em relação à "terra perdida”. Muitos se sentem enganados pelas promessas (nunca cumpridas, segundo eles) feitas pelos incorporadores imobiliários (os já mencionados gade-keepers). De fato, os moradores encaram as condiçóes do passado com o olhar experiente do presente, ou melhor, a terra de antes, o lugar do morar, onde nem mesmo cercas existiam, agora é lembrada como espaço abstrato, geometrizado em lotes, (a terra que agora pode ser aferida em reais, euros ou dólares). Diariamente convivem com o incômodo da herança que não existe mais. Os moradores mais jovens, municiados pelas histórias contadas por seus pais e avós, admitem a ingenuidades de seus antepassados, justificando que eles, à época, jamais imaginariam o que estava por vir.

Os moradores olham para o lugar de hoje e descrevem o de suas lembranças. Citam as casas de palha, que distribuídas aleatoriamente, pontilhavam os areais. As terras a beira-mar não eram lugar de habitação, mas das palhoças que resguardavam as pequenas jangadas, assim como serviam para as conversas entre pescadores. Em relação aos contados com "o mundo exterior", foram mencionadas as poucas idas e vindas, até porque os acessos e os meios de transporte eram inexistentes ou muito precários. O sol e o querosene queimando no candeeiro eram as únicas fontes de luz.

Diante das condiçóes delineadas, acrescentadas ainda a quase ausência de serviços públicos gratuitos de outrora, os moradores louvam as infraestruturas básicas instaladas, principalmente, as estradas, os meios de transportes e de comunicação, e a eletrificação. Todavia, admitem que a maioria das "melhorias do tempo de agora" veio em função de outras atividades, e não diretamente produto de suas necessidades.

Outros avanços assinalados pelos moradores referem-se à dimensão econômica. $\mathrm{O}$ trabalho assalariado e os recursos mensais monetários são citados como ganhos, sobretudo, devido à possibilidade do aumento do consumo. Essa afirmação não surpreende à medida que os próprios moradores afirmam ser cada vez mais difícil "buscar sustento" (reprodução biológica e social) nas atividades primárias e artesanais de antes (a pesca, a mariscagem, as pequenas plantaçóes, as pequenas criaçóes animais). Há nos jovens uma crítica no que tange as alternativas sócio-ocupacionais. Para estes não sobram muitas escolhas senão as profissôes de caseiro (serviços gerais) e garçom.

$\mathrm{Na}$ maioria dos discursos percebe-se, no dito e no não dito, que os moradores acreditam no seu papel de coadjuvantes nos processos que agora definem suas vidas. As condiçóes atuais são para eles um produto de uma exterioridade, não vendo em si mesmos, potencialidades para definir o que precisam e como alcançar o desejado. Empiricamente, reconhecem problemas sociais que os atingem atualmente (medo da potencial criminalidade, prostituição e aumento do custo de vida), os veem como subprodutos das mudanças socioespaciais destacadas, porém, instantaneamente, voltam a condição de seres conduzidos por um destino predefinido. 
Nas localidades promotoras de um modelo de organização local resistente à comercialização da terra, o discurso não é homogêneo. Há conflitos de interesses entre os moradores. Isso decorre fundamentalmente porque mesmo tornando a divisão da propriedade da terra uma decisão comunitária, as condiçóes infraestruturais presentes nestas localidades são inferiores as apresentadas nas demais. Para os moradores contrários a atual situação, se a praia estivesse aberta a instalação dos mais diferentes empreendimentos privados de lazer a economia na localidade seria mais dinâmica. De fato, o modelo de organização comunitária é recente, e não há, segundo os líderes comunitários, parcerias reais com os poderes públicos locais e estaduais. Ainda segundo os líderes comunitários, a maioria da população é favorável ao bloqueio da negociação de terras.

A dificuldade em organizar fontes alternativas de uma economia solidária nas comunidades é mais um obstáculo à produção de níveis maiores de autonomia popular. Para gerar maior coesão social em relação a elaboração de modelos de organização social, uma proposta interessante seria a organização de fóruns municipais com as distintas comunidades e moradores que habitam as zonas de praia. A exposição comum dos problemas e das soluçóes encontradas mediaria a tomada de decisóes futuras, assim seriam esclarecidos acerca de que açóes são adequadas ou não para cada caso.

A visão dos moradores mais recentes, muitos deles atraídos pelo incremento das atividades turísticas e de vilegiatura, diferentemente das dos demais, é fundamentada unicamente pela situaçáo presente. Neste sentido, este perfil de morador defende a contínua "modernização" da localidade, ou seja, abertura total ao processo de implantação de empreendimentos turísticos e imobiliários. Acreditam inclusive que esse caminho, mesmo produzindo ganhos indiretos aos moradores, é mais eficaz do que açóes contrárias ao aumento do número de visitantes e vilegiaturistas. Veem os problemas derivados comuns a qualquer lugar e, desta forma, toleráveis. Acreditam, ainda, que a presença dos "de fora" significa uma fonte de ajuda e atração de muitos benefícios.

Os relatos dos moradores possibilitam uma caracterização dos vacanciers, especialmente, dos vilegiaturistas. Inicialmente, mencionam os pioneiros, os vilegiaturistas metropolitanos. Basicamente, nas comunidades onde instalaram suas villas os vilegiaturistas dos primeiros anos de expansão ficaram conhecidos como os "doutores" e "patrôes". Nem todos eram médicos ou advogados, mas a população local encontrou nestas formas de tratamento maneira de demonstrar seu respeito àqueles que chegavam e que demonstravam mais escolaridade, influência e posses. Com o tempo, tornaram-se reconhecíveis pela população, inclusive interagindo, seja pela contratação de serviços (daí o termo patrão) ou pela prestação de favores. São inúmeros os relatos: médicos que atendiam em suas residências e doavam medicamentos; outros contribuíam com recursos financeiros para festas de padroeiro; mediavam o acesso dos moradores a serviços na Capital, inclusive proporcionando a empregabilidade de alguns. Este contexto leva os moradores a reconhecer que os vilegiaturistas que se instalavam a vinte ou trinta anos eram mais ostentosos. Segundo os moradores, aqueles buscavam na estada a tranquilidade e o descanso. 
Numa visão contemporânea do processo, os locais admitem a popularização dos visitantes, e com um tom de preconceito, afirmam ser crescente a chegada dos visitantes considerados pão-com-mortadela. Essa expressáo define os visitantes que não se preocupam com a qualidade das acomodaçôes, buscam agitação, sol e diversão, economizando ao máximo os gastos com a estada. Até mesmo as segundas residências adquiridas são menores e sem requintes arquitetônicos.

Em relação à dinâmica imobiliária, os comerciantes locais afirmam que o modelo anterior, onde ocorria, predominantemente, a autoconstrução de casas individuais, era mais benéfico à economia da comunidade, tanto pela comercialização de produtos como pela contratação de máo-de-obra local. Vale mencionar que este padrão não foi totalmente extinto, todavia tem sido rapidamente substituído pela construçáo empresarial (construtoras e incorporadoras) de condomínios.

Se os vilegiaturistas autóctones têm contribuído há décadas na redefinição da cotidianidade dos moradores, na última década é crescente a participação dos estrangeiros nesta tessitura. Como já mencionado, na imensa maioria das comunidades visitadas durante os trabalhos de campo confirmou-se a presença de estrangeiros (tanto vilegiaturistas, quanto moradores).

Pelos depoimentos, os moradores demonstram o estabelecimento de marcos diferenciadores entre os vilegiaturistas locais e os estrangeiros. Em primeiro lugar, "os gringos" são classificados como turistas. Indagados acerca dos critérios utilizados, os locais remetem as categorias distância e nacionalidade: o turista é aquele que veio de longe, sua "fala" é estranha, é exótico, é diferente. A língua é realmente um dos principais impeditivos do estabelecimento de relaçóes de sociabilidade. As exploraçóes realizadas permitem afirmar que é muito reduzido o número de moradores falantes de outras línguas que não seja a materna. Isso, em parte, pode explicar a caracterização dos vilegiaturistas alóctones como reservados e pouco interessados em estabelecer contatos de sociabilidade com os locais. Os vilegiaturistas que de fato não planejam maior proximidade as populaçóes locais adquirem seus imóveis (ou locam) nos empreendimentos tipo condomínio e resorts, onde já há proprietários (ou locatários) da mesma nacionalidade. Essa nuança do processo é constatada com franceses em Águas Belas, e com escandinavos em Taíba, em Cumbuco e também em Porto das Dunas.

Explicado o caso geral, há, contudo, exceções. Os moradores de comunidades como Taíba, Iguape, Caponga e Colônia descrevem os considerados "desbravadores". Estes são estrangeiros que chegaram primeiro (e continuam a atrair outros), antes, inclusive, dos novos condomínios e resorts. Eles estabeleceram relaçóes comerciais com vilegiaturistas autóctones ou proprietários locais, adquiriram casas usadas e terrenos, tornaram-se reconhecíveis pela comunidade, e alguns apreenderam a língua portuguesa e/ou ensinaram sua língua de origem. Indo além dos quesitos básicos de convívio e sociabilidades, há muitos casos de estabelecimentos de relaçôes amorosas legalizadas entre vilegiaturistas alóctones e moradores. Aqui não é possível quantificar a intensidade deste fenômeno, porém efetivamente se admite que tal situação tenha como um dos desdobramentos a migração definitiva de estrangeiros e também de locais.

Os moradores reconhecem que a efetivação dos estrangeiros como vilegiaturistas (principalmente, por serem possuidores de imóveis) e, como efeito, o alongamento 
dos períodos de estada (de semanas para meses), adiciona a dinâmica social das localidades novas demandas por lazer durante temporadas distintas das praticadas pelos vilegiaturistas e turistas locais. Se pelos investimentos e frequentadores as localidades se internacionalizam, pelas diferentes demandas, o tempo nestas comunidades é reestruturado em função da diversidade de sujeitos sociais.

Finalizar este texto interagindo com o discurso e as apreensôes dos moradores não foi fato despretensioso. Inegavelmente, os novos e os velhos padróes de consumo do espaço em função do desejo dos vacanciers aceleram o processo de criação da rede metropolitana de lugares litorâneos disponíveis. Nos lugares, isso significa mudanças econômicas, sociais e culturais. Contudo, há um alerta: tais transformaçôes serão democráticas quando o discurso científico e o planejamento tecnocrático, de fato, ouvirem e consideram como importantes às análises, os desejos e as objeçóes elaboradas pelos diferentes grupos de moradores.

\section{Consideraçóes finais}

O espaço litorâneo do Nordeste do Brasil é reconhecido por suas praias arenosas, pelos vários dias ensolarados e também pelas águas mornas do Atlântico. Sobre a planície litorânea erguem-se vias rodoviárias, condomínios, completos turísticos imobiliários, resorts. Assim, são atraídos milhares de turistas e vilegiaturistas que demandam as benesses do local, associadas a um espaço urbanizado com as infraestruturas próprias das aglomeraçóes citadinas. Como planejar estes espaços? Quais demandas devem ser atendidas como prioridade, as dos visitantes ou dos moradores? Como as municipalidades e as demais esferas administrativas compreendem esses fluxos sazonais? Estas questôes foram alvo das análises empreendidas neste texto.

Em termos de planejamento, as administrações públicas no Nordeste e seus tecnocratas, atentando ao planejamento do setor privado (turístico e imobiliário), devem repensar a produção do espaço litorâneo, levando em consideração a urbanização crescente e ao mesmo tempo a variedade de usos e usuários. Neste sentido, o desenvolvimento da vilegiatura marítima (e das demais práticas marítimas modernas) não pode ocorrer em detrimento dos interesses dos residentes destes espaços, até porque as incorporadoras imobiliárias já planejam um espaço litorâneo híbrido, marcado pelo turismo, pela vilegiatura, e também pelo morar permanente.

Com a alocação constante de recursos públicos em infraestrutura no espaço metropolitano e o marketing proporcionado pela divulgação dos lançamentos imobiliários, é prudente afirmar que a vilegiatura marítima tenderá a manter-se concentrada no litoral da RMF, seguindo modelo semelhante ao que ocorre em outras metrópoles nordestinas. O imobiliário turístico é uma realidade crescente, mesmo diante das crises econômicas mundiais, produzindo a curto e médio prazos novos empreendimentos no litoral da Regiấo Metropolitana de Fortaleza.

O planejamento técnico dos empreendedores e o posicionamento dos governos locais apontam para consolidação da fragmentação espacial do tecido urbano litorâneo. Situação articulada à promoção de modelos urbanísticos que valorizam o uso dos espaços privados em detrimento do espaço público. Esse é um dos maiores problemas, haja vista a constataçáo de precariedades infraestruturais nos espaços 
externos aos empreendimentos (saneamento básico, pavimentação de vias e serviços públicos de saúde).

A respeito dos moradores do litoral (comunidades tradicionais ou não), no Nordeste ainda é tímida a participação destes sujeitos na elaboração da legislação, como também na alocação de recursos públicos. As medidas mitigadoras apresentadas nos planos de instalação dos empreendimentos turísticos imobiliários não contemplam os problemas derivados de sua instalação. Todavia, vale mencionar que existem exemplos de comunidades pequenas organizadas em função da crítica ao modelo de atividade econômica pensada para o litoral. Alguns já conseguiram inclusive a proteção de suas terras através de decretos federais e instituição de unidades de conservação de uso sustentável.

É inequívoco afirmar que um modelo único não supre as necessidades socioeconômicas do litoral metropolitano Nordestino. Desta forma, é preciso debater cada proposta tanto da iniciativa pública como privada.

\section{Referências bibliográficas}

Cazelais, N. (2009). L'espace touristique: relations entre résidents, visiteurs et paysages. Ateliê Geográfico, 3(1), 179-193. doi: 10.5216/ag.v3i2.7325

Cumbrera, M. G. \& Lara, E. L. (2010). Consecuencias del turismo de masas en el litoral de Andalucía (España). Caderno Virtual de Turismo, 10(1), 125-135. http://www.redalyc. org/pdf/1154/115412537010.pdf

Daligaux, J. (2003). Urbanisation et environnement sur les littoraux: une analyse spatiale. Rives méditerranéennes [En ligne], (15), 1-8. https://rives.revues.org/12

Dantas, E. (2013). Touristic metropolization in an industrialized region by monoculture. Revista Mercator, 12(2), 65-84. doi: 10.4215/RM2013.1202. 0005

Debié, F. (1993). Une forme urbaine du premier age touristique: les promenades littorales. MappeMonde, (1), 32-37.http://www.mgm.fr/PUB/Mappemonde/M193/PROMENAD. pdf

Harvey, D. (2004). Espaços de Esperança. São Paulo: Loyola.

Instituto Brasileiro de Geografia e Estatística (IBGE). (2008). Regiōes de influências das cidades 2007-REGIC. Rio de Janeiro: IBGEL. http://www.ibge.gov.br/home/geociencias/ geografia/regic.shtm?c=7

Instituto Brasileiro de Geografia e Estatística (IBGE). (2011). Censo Demográfico 2010. Sinopse do Censo e Resusltados Preliminares do Universo. Rio de Janeiro: IBge. http://www.ibge. gov.br/home/presidencia/noticias/imprensa/ppts/0000000402.pdf

Instituto de Pesquisa e Estratégia Econômica do Ceará (IPECE). (2012). Perfil Básico Regional 2012: Região metropolitana de Fortaleza. Fortaleza, Brasil: IPECE. http://www2.ipece. ce.gov.br/estatistica/perfil_regional/Perfil_Regional_R1_RMF_2012.pdf

Lefevbre, H. (2001) A revolução urbana. Belo Horizonte: Edufmg (Editora da Universidade Federal de Minas Gerais).

Lefevbre, H. (1991). A vida cotidiana no mundo moderno. São Paulo: Ática. 
Ministério do Meio Ambiente do Brasil (MмAB), Secretaria de Qualidade Ambiental (sQA)/ Ministério do Planejamento, Orçamento e Gestão (MPOG), Secretaria do Patrimônio da União (spu). (2002). Projeto Orla: fundamentos para gestâo integrada. Brasilia: MMAB/MPOG. http://bit.ly/2bTsyVH.

Müller, D. K., Hall, C. M. \& Keen, D. (2008) Second home tourism impact, planning and management. In C. M. Hall \& D. R. Müller (Eds.), Tourism, mobility and second homes: between elite landscape and common ground (pp. 15-34). Clevedon, uK: Channed View Publications.

Pereira, A. Q (2014). A urbanização vai à praia. Fortaleza, Brasil: Ediçôes ufC (Editora da Universidade Federal do Ceará). http://bit.ly/2bYz80F

Pereira, A. Q. \& Dantas, E.W.C. (2008). Veraneio marítimo na metrópole: o caso de AquirazCeará-Brasil. Sociedade \& Natureza, 20(2), 93-106. http://www.redalyc.org/articulo. oa?id=321327193002

Projeto Orla. Vide Ministério do Meio Ambiente do Brasil (ммав) ... (2002). http://bit. ly/2bTsyVH

Silva, J. B. (2007). Regiáo metropolitana de Fortaleza. In J. Bozarchiello da Silva, T. C. Cavalcant \& E. W. C. Dantas (Orgs.), Ceará: um novo olhar geográfico (pp. 101-124). Fortaleza, Brasil: Demócrito Rocha. 
